\title{
Hydrogen isotope compositions in carbonado diamond: constraints on terrestrial formation
}

\author{
Attila Demény, Géza Nagy \\ Bernadett Bajnóczi, Tibor Németh \\ Institute for Geochemical Research \\ Hungarian Academy of Sciences, Budapest
}

Vadym Drozd

CeSMEC

Florida International University, Miami

\author{
József Garai \\ Department of Mechanical and \\ Materials Engineering \\ International University, Miami
}

\author{
Ernst Hegner \\ Dept. für Geo- und Umweltwissenschaften \\ Ludwig-Maximilians Universität, München
}

In this study we report the first hydrogen isotope composition analyses on carbonado diamond along with cathodoluminescence and scanning electron microscopic imaging, electron microprobe analyses, and stable ( $\mathrm{H}$ and $\mathrm{C}$ ) and radiogenic ( $\mathrm{Sr}$ ) isotope measurements. The hydrogen of bulk carbonado (consisting diamond and pore-filling minerals) yielded $\sim-4 \%$, consistent with usual crustal or mantle-derived fluids. The diamond-related hydrogen component is about $70 \pm 30 \mathrm{ppm}$ and shows a D-depletion down to $-200 \%$. Determined H isotope values - together with C isotope compositions - overlap the ranges for mantle-derived hydrocarbons. Textural characteristics and $\mathrm{Sr}$ isotope ratios of pore-filling florencite indicate that the carbonado was formed in a fluid-rich environment, underwent a significant high-temperature influence and finally suffered thorough alteration. Based on these observations, a terrestrial formation during interaction of mantle rocks/melts or subducted crustal materials and reduced $\mathrm{C}-\mathrm{H}$ fluids seems to be more plausible than an extraterrestrial origin.

Key words: carbonado, diamond, hydrogen isotope composition, carbon isotope composition, Sr isotope ratio, texture, cathodoluminescence microscopy

\section{Introduction}

Carbonado diamond, a special microcrystalline diamond variety that is found in placer deposits in Brazil and the Central African Republic (Trueb and

\footnotetext{
Addresses: A. Demény, G. Nagy, B. Bajnóczi, T. Németh: H-1112 Budapest, Budaörsi út 45, Hungary e-mails: demeny@geochem.hu,gnagy@geochem.hu,bajnoczi@geochem.hu, ntibi@geochem.hu

J. Garai: Miami, FL 33199, USA, e-mail: jozsef.garai@fiu.edu

D. Vadym: Miami, FL 3319, USA, e-mail: vdrozd@gmail.com

H. Ernst : Luisenstr. 37, D-80333 München, Germany, e-mail: hegner@lmu.de

Received: April 18, 2011; accepted: May 16, 2011
} 
Butterman 1969), has a number of unique features that distuinguish it from other diamond types (e.g., restricted to single time and locality, porphyroclastic and highly porous microstructure, narrow stable carbon isotope composition range of about $-27 \pm 3 \%$ ) (see the comprehensive review by Heaney et al. 2005). Although the literature is extensive, there is no general consensus regarding the origin of carbonados. Genetical models are extremely varied: formation from organic matter due to subduction-related metamorphism (Robinson 1978) or extreme nuclear irradiation (Kaminsky 1987; Ozima et al. 1991; Ozima and Tatsumoto 1997), precipitation from carbonic fluids in the mantle (Kaminsky 1991; Nadolinny et al. 2003), or an impact origin either by transforming terrestrial organic matter into diamond (Smith and Dawson 1985) due to the impact shock or transporting extraterrestrial diamondiferous material (Haggerty 1996, 1999; Garai et al. 2006). The presence of hydrogen trapped in the diamond structure has recently been discovered in carbonado (Nadolinny et al. 2003; Garai et al. 2006; Kagi and Fukura 2008). Based on the resemblence of FTIR absoption spectra to those of presolar and CVD (chemical vapor deposition) diamonds, the hydrogen content was interpreted as an evidence for formation in a hydrogenrich interstellar environment (Garai et al. 2006). An extraterrestrial origin has been suggested for carbonado on the base of those features which are distinct from terrestrial - especially mantle-derived - diamonds: close areal distribution, low carbon isotope composition, green and orange cathodoluminescence colour, high porosity, elevated concentrations of PAHs, occurrence of native metals, titanium and boron nitrides and planar-defect lamellae, lack of primary mantle mineral inclusions (Jones et al. 2003; Parthasarathy et al. 2005; Garai et al. 2006). Additionally, the carbonado grains have a smooth, glossy surface that has been interpreted as "fusion crust" formed during a bolide impact (Shelkov et al. 1997; Kletetschka et al. 2000). The arguments for extraterrestrial origin have been weakened by recent observations published in the last several years: osbornite (TiN) has been shown to form in deep subduction environment (Dobrzhinetskaya et al. 2007), deformation lamellae have been produced experimentally at mantle P-T conditions in carbonado diamond (De et al. 2004), green and yellow CL colours have been encountered in terrestrial diamonds (De Stefano et al. 2006), native metals have been described in kimberlite-hosted diamonds (Jacob et al. 2004 and references therein), diamonds with very low carbon isotope compositions (down to $-41 \%$ o relative to V-PDB, Cartigny et al. 2004; Cartigny 2007, 2008; De Stefano et al. 2009), low aggregation states (Cartigny 2007, 2008; Kagi and Fukura 2008) and elevated hydrogen contents (Hayman et al. 2005) have been reported from various types of mantle-derived diamonds. The latter observation is important as the hydrogen content of the carbonado diamond can provide new means to investigate its origin. Assuming an extraterrestrial origin, $\mathrm{D} / \mathrm{H}$ ratios may be used to infer the ultimate origin of the $\mathrm{H}$ component, as it should either be strongly depleted in deuterium (solar hydrogen) or enriched in deuterium (interstellar organic matter from which the 
diamond may have formed) (see reviews by Aléon and Robert 2004; Huss 2005). Until now, the major obstacle of such study has been the low hydrogen content of the carbonado, which itself is usually avaliable only in very small quantities. Recent technical developments now makes it possible to analyse very small amounts of hydrogen extracted from minerals (Demény and Siklósy 2008).

The main aim of this study was to determine the amount and hydrogen isotope composition of the $\mathrm{H}$ compounds contained in carbonados, and the interpretation of these data in the light of carbonado origin, for which purpose five carbonado samples from Brazil and Central Africa were studied. However, as usual in stable isotope geochemistry, for the correct interpretation of hydrogen isotope data detailed investigations on sample characteristics are needed. This is especially true for the smooth surface, since the assumed fusion process (Shelkov et al. 1997; Kletetschka et al. 2000) cannot only provide arguments for an impactrelated origin, but can also cause modifications in the original hydrogen content and isotope compositions by degassing. Carbon isotope analyses are also essential in order to demonstrate the typical carbonado nature of the selected samples. As mentioned above, carbonado is special among diamond classes for its mineral inclusion content. The volumetrically most important mineral within the diamond is florencite $\left[(\mathrm{Ce}, \mathrm{REE}) \mathrm{Al}_{3}\left(\mathrm{PO}_{4}\right)_{2}(\mathrm{OH})_{6}\right]$, whose presence indicate hydrothermal conditions (Trueb and de Wys 1971). Its coexistence with kaolinite suggest alteration (Trueb and de Wys 1971) from a precursor mineral (like monazite, also reported from carbonado, Trueb and de Wys 1971). The florencite is rather Sr-rich (up to $8.7 \mathrm{wt} \% \mathrm{SrO}$; De et al. 1998). Although the rare earth element (REE) compositions of Brazilian and African carbonado reflect crustal origin for the REE-bearing minerals, such high Sr content raises the possibility of partial preservation of the original strontium if the precursor mineral (e.g. monazite) was formed in a different environment (mantle or extraterrestrial). Thus, Sr isotope ratios were also determined in acid-leached fraction.

Based on these considerations, this paper presents a complex study on textural features, chemical and isotope compositions investigated by means of optical and cathodoluminescence (CL) microscopes, electron microprobe, and mass spectrometric (for $\mathrm{H}, \mathrm{C}$ and $\mathrm{Sr}$ isotopes) analyses.

\section{Samples and analytical techniques}

Five carbonado samples from Brazil (sample BR-H) and the Central African Republic (samples CAR-J2, CAR-J4, CAR-J5 and CAR-3), weighing about $200 \mathrm{mg}$ each, were investigated. Measurement of more samples was precluded by the amount needed and the destructive nature of analyses. The samples were purchased and hence only approximate location coordinates can be given: $\mathrm{E}$ 15-25 and N 5-10 for the Central African Republic; W 37-47 and S 10-20 for Brazil. All analyses (excepting where stated otherwise) were conducted at the Institute for Geochemical Research, Budapest. Cathodoluminescence 
microscopic characteristics were studied using Reliotron type cold-cathode equipment attached to a Nikon Eclipse E600 optical microscope equipped with a Nikon Coolpix 4500 digital camera. Major element compositions of pore-filling minerals were determined with a JEOL Superprobe 733 electron microprobe. Conditions used were: wavelength dispersive spectrometers, $15 \mathrm{kV}$ accelerating voltage and $30 \mathrm{nA}$ beam current. Raw data was corrected using the ZAF correction program provided by JEOL.

A Philips PW 1730 X-ray diffractometer controlled by PC-APD software was used for routine X-ray diffractometric analyses to identify mineral phases and to check the efficiency of acid treatment. In order to detect trace amounts of minerals, X-ray diffraction analyses were also conducted at B2 station of Cornell High Energy Synchrotron Source (CHESS), using synchrotron X-rays with a wavelength of $\lambda=0.4959 \AA$ and a Mar345 image plate detector. 2D diffraction patterns obtained were integrated using Fit2D software. The detection limit of minerals for usual XRD analysis is about $3 \mathrm{vol} \%$, whereas the synchrotron-based XRD analysis has a much lower detection limit due to higher signal-to-noise ratio, below 1 vol\%.

For carbon isotope analyses, about $2 \mathrm{mg}$ of powdered (down to $<0.1 \mathrm{~mm}$ grain size) and acid-treated $(1: 1 \mathrm{HCl})$ carbonado diamond samples were mixed with $\mathrm{CuO}$ and combusted at $1000{ }^{\circ} \mathrm{C}$ for 60 minutes, then the evolved $\mathrm{CO}_{2}$ was purified by vacuum distillation and the carbon isotope compositions were determined using a dual inlet Finnigan MAT delta $S$ type mass spectrometer. The results were calibrated using in-house standards and the $\mathrm{CH}-7$ reference material supplied by the International Atomic Energy Agency.

For hydrogen isotope analyses different types of materials were prepared from 5 carbonado samples: 1) bulk, untreated carbonado, powdered or chips of 1-2 mm size; 2) powdered samples treated with $\mathrm{HCl}$ and $\mathrm{HF}$ acids; 3 ) powdered, but chemically untreated sample stepwise heated to 500,1000 and $>1500^{\circ} \mathrm{C}$. In order to remove silicate and phosphate minerals, powdered samples were dissolved in $\mathrm{HCl}$ for $1-3$ days at $50{ }^{\circ} \mathrm{C}$ followed by washing with distilled water, then the remaining material was treated with $\mathrm{HF}$ for 3 days at $90-100{ }^{\circ} \mathrm{C}$ and washed again with distilled water. For bulk analyses samples weighing 30 to $50 \mathrm{mg}$ were put into $6 \mathrm{~mm}$ silica tubes and attached to the vacuum preperation line modified after Demény and Siklósy (2008), by inserting a silica tube containing $\mathrm{CuO}$ between the sample and gas-collection cold fingers (see Fig. 1). The $\mathrm{CuO}$ was constantly held at $600{ }^{\circ} \mathrm{C}$ to produce an oxygen atmosphere of about $0.5 \mathrm{mbar}$ in the vacuum line that allowed conversion of all hydrogen released to $\mathrm{H}_{2} \mathrm{O}$. After pumping to good vacuum (while the sample was held at $150{ }^{\circ} \mathrm{C}$ for 8 hours to get rid of surface-bound $\mathrm{H}_{2} \mathrm{O}$ ), the sample was slowly heated to $1500-1700{ }^{\circ} \mathrm{C}$ (elastic temperature of silica) using a gas-oxygen torch. The heating time was about 30 minutes. Very slow diffusion may partially retain hydrogen in the diamond structure resulting in incomplete yield, but graphitization and oxidation can effectively disrupt the crystal structure promoting $\mathrm{H}$ release (e.g. similarly to He, 


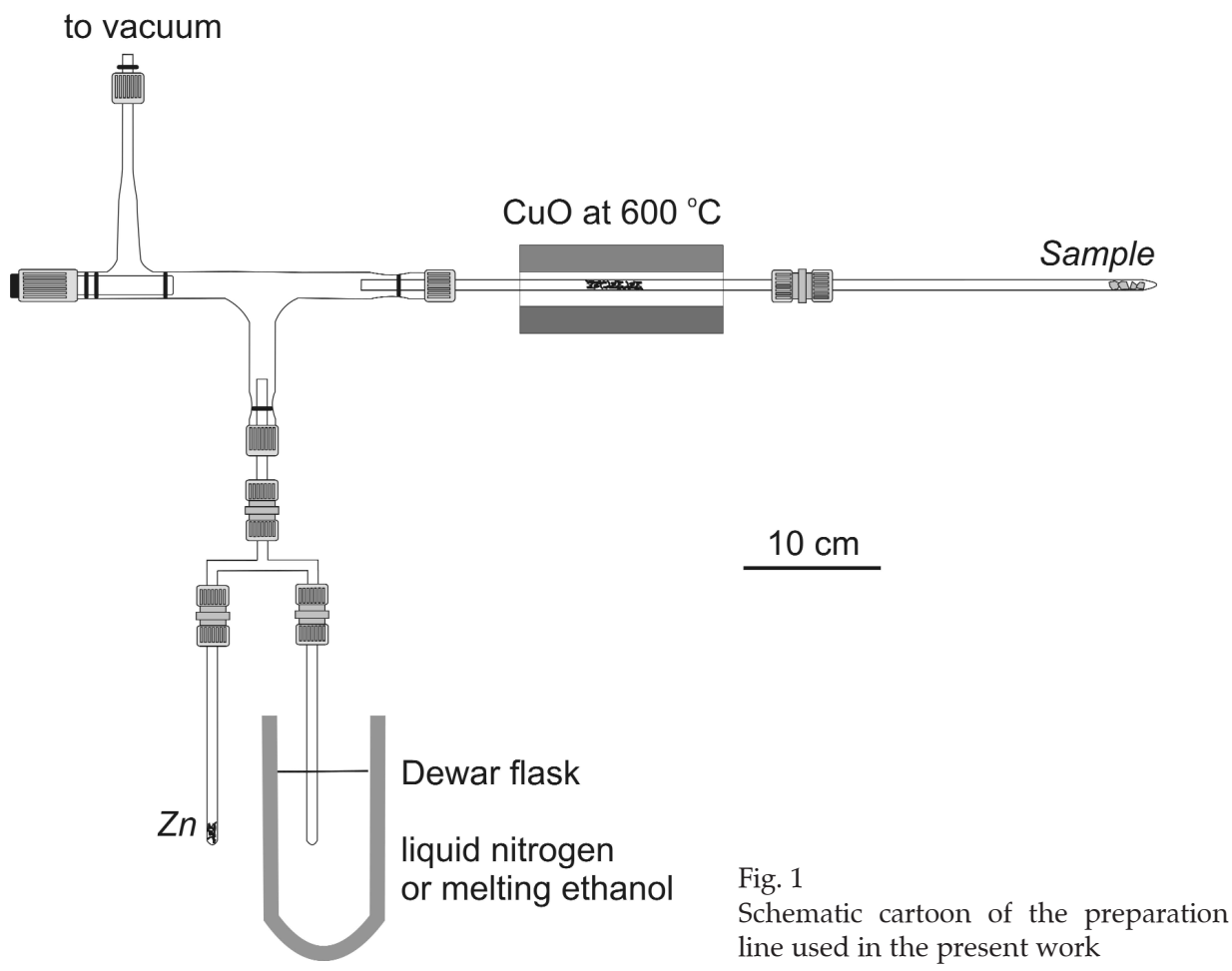

Zashu and Hiyagon 1995). The agreement in $\mathrm{H}$ contents and isotope compositions for different analytical conditions supports complete hydrogen recovery. The gases evolved were collected at liquid nitrogen temperature in a 6 $\mathrm{mm}$ pyrex tube for another 15 minutes in order to convert all the released hydrogen to $\mathrm{H}_{2} \mathrm{O}$, then the temperature was raised to about $-80{ }^{\circ} \mathrm{C}$ and the noncondensible gases were pumped away. The collected $\mathrm{H}_{2} \mathrm{O}$ was transferred to another $6 \mathrm{~mm}$ pyrex tube containing zinc reagent (Indiana University, Bloomington), then the tube was flame-sealed and put into a muffle furnace to $480{ }^{\circ} \mathrm{C}$ to convert $\mathrm{H}_{2} \mathrm{O}$ to $\mathrm{H}_{2}$ gas (see Demény 1995; Demény and Siklósy 2008). The $\mathrm{D} / \mathrm{H}$ ratios were analysed in the $\mathrm{H}_{2}$ gas using a Thermo Finnigan delta XP mass spectrometer using a GASBENCH II equipment as a tube-cracker and inlet port (see Demény and Siklósy (2008) for the manual measurement protocol). As one of the reviewers kindly called our attention, hydrogen can diffuse through heated silica even at rather low temperature $\left(<300{ }^{\circ} \mathrm{C}\right.$, Shang et al. 2009), contamination from the ambient atmosphere may occur especially at the high temperatures used in this study, thus, determination of blank level is important to assess the analyses' accurracy. Blank measurements were conducted twice during this study, yielding about 0.5 micromole $\mathrm{H}_{2}$. For general sample weights 
and $\mathrm{H}$ contents obtained for the carbonado samples this blank causes $<10 \%$ contamination.

Hydrogen and carbon isotope compositions are reported in the conventional $d$ value given by the equation: $\delta=\left(R_{\text {sample }} / R_{\text {standard }}-1\right) \cdot 1000$, where $R_{\text {sample }}$ and $\mathrm{R}_{\text {standard }}$ are the $\mathrm{N}(\mathrm{D}) / \mathrm{N}(\mathrm{H})$ and $\mathrm{N}\left({ }^{3} \mathrm{C}\right) / \mathrm{N}\left({ }^{12} \mathrm{C}\right)$ ratios of the sample and standard, respectively. The data are reported in \%o relative to V-SMOW ( $\delta \mathrm{D}$ values) and V-PDB ( $\left({ }^{13} \mathrm{C}\right.$ values). Based on duplicate analyses on samples and standards the carbon isotope compositions are accurate within $0.2 \%$. The accuracy of hydrogen isotope analyses was determined as follows.

The $\mathrm{H}$ isotope composition of blank-derived hydrogen was also determined by collecting $\mathrm{H}_{2} \mathrm{O}$ in the same vacuum line for 2 hours in order to get enough material for precise measurements. This procedure is periodically followed when $\mathrm{H}$ isotope analyses are conducted in the laboratory and using the preparation line, the long-term blank composition is $-100 \pm 10 \%$. Using the amount and composition of blank-derived hydrogen, the data obtained on samples were corrected. The usual blank correction was 2-3\%o and rarely exceeded 5\%o. The same procedure as for the diamond samples was followed for the NBS 30 biotite reference material. Amounts of 2.3 to $4.5 \mathrm{mg}$ were weighed into the silica tubes in order to span the whole range of $\mathrm{H}_{2} \mathrm{O}$ amounts recovered from the carbonado samples to reproduce the preparation conditions. A $\delta \mathrm{D}$ value of $-65.6 \pm 1.9 \%$ ond a water content of $3.35 \pm 0.35 \mathrm{wt} \%(2 \mathrm{~s}, \mathrm{n}=4)$ was obtained in the course of this study (theoretical compositions are $\delta \mathrm{D}=-65.7 \%, \mathrm{H}_{2} \mathrm{O}=3.5 \mathrm{wt} \%$ ). As the NBS 30 analyses were conducted along with the sample preparations, the excellent agreement between measured and expected compositions verify the procedure. The sample amounts available precluded multiple analyses for most of the samples. However, enough sample material was available for sample CAR-3, for which two bulk analyses yielded -86.1 and $-85.7 \%$. Additionally, a third batch of sample CAR-3 was step-wise heated to $500{ }^{\circ} \mathrm{C}, 1000{ }^{\circ} \mathrm{C}$ and $>1500{ }^{\circ} \mathrm{C}$ and the different $\mathrm{H}$-fractions were collected separately. The material was just at the limit of measurement, yielding very small amounts of $\mathrm{H}_{2}$ at the $>1500{ }^{\circ} \mathrm{C}$ step that enhanced the effect of blank contamination and resulted in very large degrees of blank correction (up to $50 \%$ ). However, the bulk composition was also calculated for the step-wise combustion experiment on the base of hydrogen yields that gave $-85.3 \%$, in excellent agreement with the duplicate bulk analyses (-86.1 and $-85.7 \%$ ) in spite of the enormous blank correction. Based on these data, the analytical precision for $\delta \mathrm{D}$ analyses is better then $\pm 3 \%$, as a conservative estimation. The precision of $\mathrm{H}$ content determination is about $10 \%$ for the biotite sample and about $20 \%$ for the carbonado.

For Sr isotope analyses the sample powders were dissolved in $\sim 0.5 \mathrm{~N} \mathrm{HCl}$ and Sr was separated by standard chromatographic methods. The Sr-isotope analyses were carried out at Ludwig-Maximilians Universität München, using standard procedures outlined by Hegner et al. (1995). Total procedure blanks are $\sim 200 \mathrm{ng}$ and not significant for the samples under investigation. ${ }^{87} \mathrm{Sr} /{ }^{86} \mathrm{Sr}$ ratios were measured in a dynamic double mass collection mode using a MAT 261 and 
normalized to ${ }^{86} \mathrm{Sr} /{ }^{88} \mathrm{Sr}=0.1194$. External precision for ${ }^{87} \mathrm{Sr} /{ }^{86} \mathrm{Sr}$ is $\sim 1.1 \times 10^{-5}$. The NIST 987 reference material yielded ${ }^{87} \mathrm{Sr} /{ }^{86} \mathrm{Sr}=0.710229 \pm 6(\mathrm{~N}=11)$.

\section{Results}

The most important textural observations made by optical and CL microscopic as well as electron microprobe investigations are the following: (1) the carbonados show angular shapes rounded to different degrees (Fig. 2); (2) a recrystallized zone of some 10 s of microns is sometimes formed at the smooth,

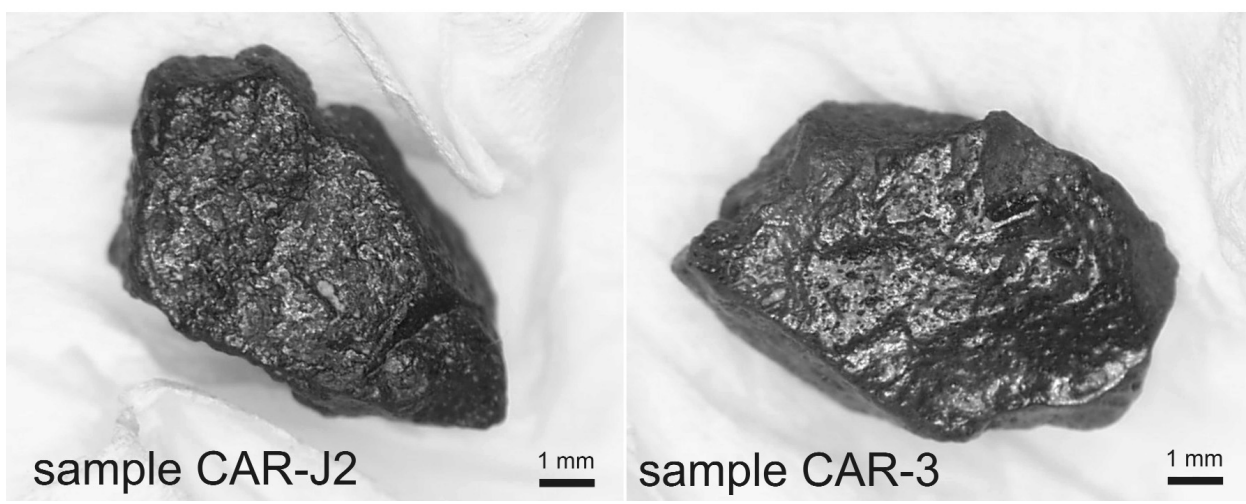

Fig. 2

Stereo microscopic pictures of carbonado samples. Note the angular shape, glossy surface and rounded edges

"glassy" looking surface (Fig. 3A); (3) the thickness of recrystallized zone changes at different sides of the carbonado; (4) the pores' structures and the florencite filling shows no change at the rim (Fig. 3B); (5) the carbonados show "flow" texture with pores concentrating in zones angular to the smooth surface (Fig. 3C); (6) the recrystallized rim contains no exotic mineral; (7) based on EDS spectra, the chemical composition of the florencite shows no change from the smooth surface to the inner parts with several wt\% SrO contents (Table 1); (8) the smooth surface has a sharp edge to the pores and the inner surface of the pores is not smooth (Fig. 3D); (9) the different samples have different cathodoluminescence colour (Fig. 4) and (10) there is no change in cathodoluminescence properties in the recrystallized zone (Fig. $4 \mathrm{~A}$ and $\mathrm{C}$ ).

The carbonado samples had bulk $\delta^{13} \mathrm{C}$ values of -32.0 to $-24.3 \%$, which compositions fall in the range of previous investigations (Vinogradov et al. 1966; Galimov et al. 1985; Ozima et al. 1991; Kamioka et al. 1996; Shelkov et al. 1997; De et al. 2001; Kagi et al. 2007; Yokochi et al. 2008), indicating that the studied samples are typical of carbonado. Amorphous carbon (Heaney et al. 2004) with different $\mathrm{C}$ isotope composition from the bulk might be present in carbonado. This possibility was tested by heating up few samples to $500{ }^{\circ} \mathrm{C}$ in oxygen 
atmosphere which should oxidize the amorphous carbon. The experiment yielded no detectable amounts of carbon dioxide. Thus, the amount of amorphous carbon in the investigated samples is insignificant.

$\mathrm{Sr}$ isotope analyses of the $\mathrm{HCl}$-soluble fraction of two samples (CAR-J2 and J4) yielded high $\mathrm{Sr}$ isotope compositions $(\sim 0.716$ and $\sim 0.717$, respectively, Table 1$)$ that represent the $\mathrm{Sr}$ content of the pore-filling florencite.
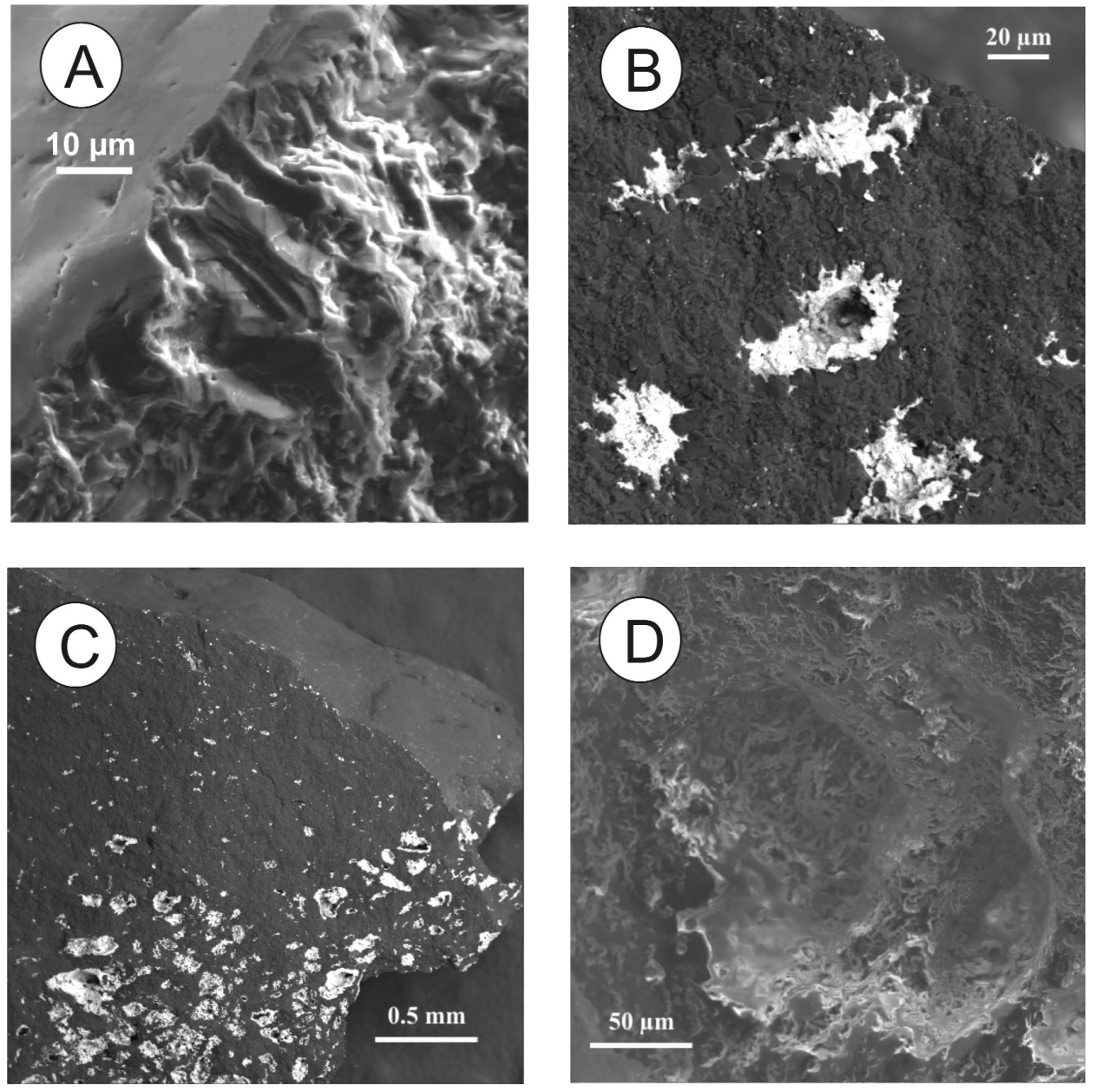

Fig. 3

Scanning electron microscope pictures of carbonado samples. (A) Sample CAR-J1, washed with distilled water, showing recrystallized margin. The upper left side is the smooth surface, the right side of the photo is a broken surface. At this part of the sample the diamond shows better crystallization at the margin than inside the grain. (B) Sample CAR-J1, washed with distilled water, showing no change in pore structure at the margin. (C) Sample BR-H, showing flow texture (see also Trueb and de Wys (1969), and Yokochi et al. (2008)) with pores concentrating in zones angular to the smooth surface. (D) Sample CAR-J2, HCl-treated. Note that the inner surface of the pore is not rounded and 

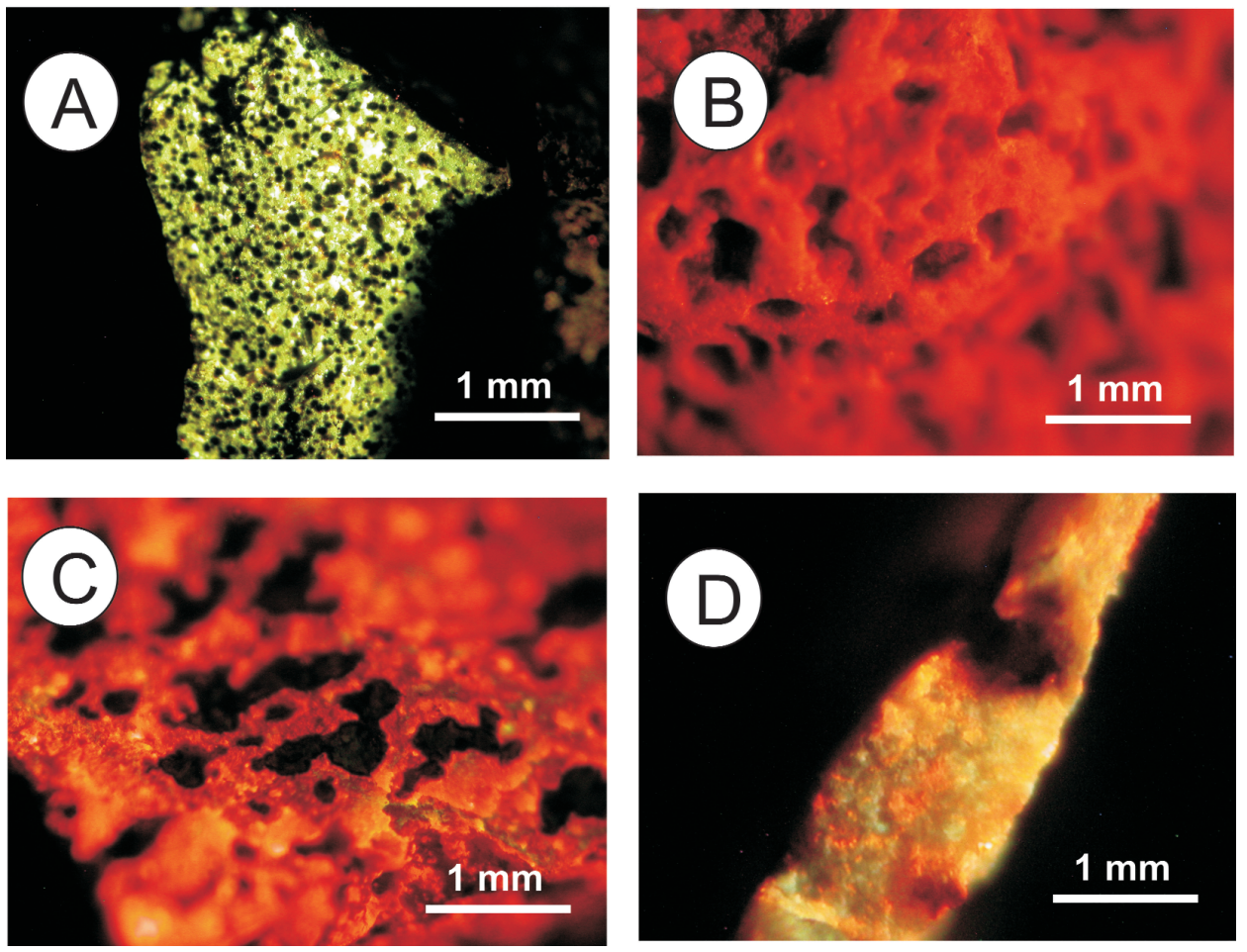

Fig. 4

Cathodoluminescence microscopic pictures of carbonado samples. (A) Sample BR-H, (B) sample CARJ1, (C) sample CAR-J2, (D) sample CAR-J3. Note that the carbonado samples have very different cathodoluminescence colours that do not change at the grains' margins

Untreated - only crushed - carbonado samples yielded a bulk hydrogen isotope composition of $-84 \pm 11 \%$, the average $\mathrm{H}$ content is $420 \pm 90 \mathrm{ppm}$. The removal of the pore filling minerals by $\mathrm{HCl}$ and subsequent $\mathrm{HF}$ acid treatment resulted in significant decrease in the $\mathrm{H}$ content as well as in the $\delta \mathrm{D}$ values. The experimental values are listed in Table 1 and shown in Fig. 5. Neither the traditional X-ray diffraction (XRD) analyses nor the synchrotron-radiation XRD measurements detected any residual mineral in the chemically treated carbonado diamond samples. Thus, the detected $\mathrm{H}$ contents as well as the $\delta \mathrm{D}$ values are intrinsic of the carbonado-diamond. As we have no direct information on the site of hydrogen, different possibilities of trapped hydrogen (as $\mathrm{H}$ or $\mathrm{OH}$ in defects or $\mathrm{H}_{2} \mathrm{O}$ in minute fluid inclusions, De et al. 1998; Kagi et al. 2010) will be treated as $\mathrm{H}$ trapped in the diamond structure.

In order to further constrain the hydrogen isotope compositions of carbonadohosted hydrogen components, stepwise heating experiments were used. Three pyrolysis steps were conducted on sample CAR-3, at 550, 1000 and $>1500{ }^{\circ} \mathrm{C}$. The "low-temperature" component released at $550{ }^{\circ} \mathrm{C}$ had a $\delta \mathrm{D}$ value of $-59 \%$, 
Table 1

Chemical compositions of selected pore-filling minerals (in wt $\%$ ), $\mathrm{H}$ contents (in ppm) and hydrogen isotope compositions (in \%o relative to V-SMOW), stable carbon isotope compositions (in \%o relative to $\mathrm{V}$-PDB) and $\mathrm{Sr}$ isotope ratios in carbonado diamonds

\begin{tabular}{|l|c|c|c|}
\hline \multicolumn{1}{|c|}{ Sample } & Florencite & Kaolinite & Xenotime \\
\hline $\mathrm{Al}_{2} \mathrm{O}_{3}$ & 27.2 & 37.5 & \\
\hline $\mathrm{SiO}_{2}$ & & 43.6 & \\
\hline $\mathrm{P}_{2} \mathrm{O}_{5}$ & 26.6 & 3.7 & 32.8 \\
\hline $\mathrm{CaO}$ & 2.5 & & \\
\hline $\mathrm{Fe} \mathrm{O}_{3}$ & & 1.7 & \\
\hline $\mathrm{CuO}$ & 1.0 & 1.4 & 0.1 \\
\hline $\mathrm{SrO}$ & 4.6 & & 38.3 \\
\hline $\mathrm{Y}_{2} \mathrm{O}_{3}$ & & & \\
\hline $\mathrm{La}_{2} \mathrm{O}_{3}$ & 8.9 & & \\
\hline $\mathrm{Ce}_{2} \mathrm{O}_{3}$ & 9.5 & 1.9 & \\
\hline $\mathrm{Nd}_{2} \mathrm{O}_{3}$ & 3.7 & & \\
\hline $\mathrm{Gd}_{2} \mathrm{O}_{3}$ & & & 3.2 \\
\hline $\mathrm{Dy}_{2} \mathrm{O}_{3}$ & & & \\
\hline $\mathrm{Er}_{2} \mathrm{O}_{3}$ & & & \\
\hline $\mathrm{PbO}^{\mathrm{Total}}$ & 2.9 & & \\
\hline $\mathrm{Total}$ & 86.8 & 89.7 & \\
\hline
\end{tabular}

\begin{tabular}{|l|c|c|}
\hline \multicolumn{1}{|c|}{ Sample } & $\mathrm{H} \mathrm{ppm}$ & $\mathrm{dD}$ \\
\hline CAR-J2 - untreated & 319 & -69 \\
\hline CAR-J2 - HCl treatment & 306 & -93 \\
\hline CAR-J2 - HF treatment & 200 & -121 \\
\hline CAR-J4- untreated & 466 & -85 \\
\hline CAR-J4 - HCl treatment & 335 & -66 \\
\hline CAR-J4 - HF treatment & 122 & -126 \\
\hline CAR-J5- untreated & 481 & -96 \\
\hline CAR-J5 - HCl treatment & 312 & -143 \\
\hline CAR-3- untreated & 222 & -85 \\
\hline CAR-3 - stepwise, 550 oC & 174 & -59 \\
\hline CAR-3 - stepwise, 1000 oC & 40 & -204 \\
\hline CAR-3 - stepwise, 1500 oC & 2 & 38 \\
\hline CAR-3 - stepwise, bulk calculated & 42 & -195 \\
\hline BR-H- untreated & 535 & -112 \\
\hline BR-H - HF treatment & 100 & -196 \\
\hline
\end{tabular}

\begin{tabular}{|l|c|c|}
\hline \multicolumn{1}{|c|}{ Sample } & $\delta^{13} \mathrm{C}$ & ${ }^{87} \mathrm{Sr}{ }^{86} \mathrm{Sr}$ \\
\hline CAR-J2 & -30.2 & 0.715977 \\
\hline CAR-J4 & -24.3 & 0.717161 \\
\hline CAR-J5 & -25.2 & \\
\hline CAR-3 & -32.1 & \\
\hline BR-H & -32.0 & \\
\hline
\end{tabular}




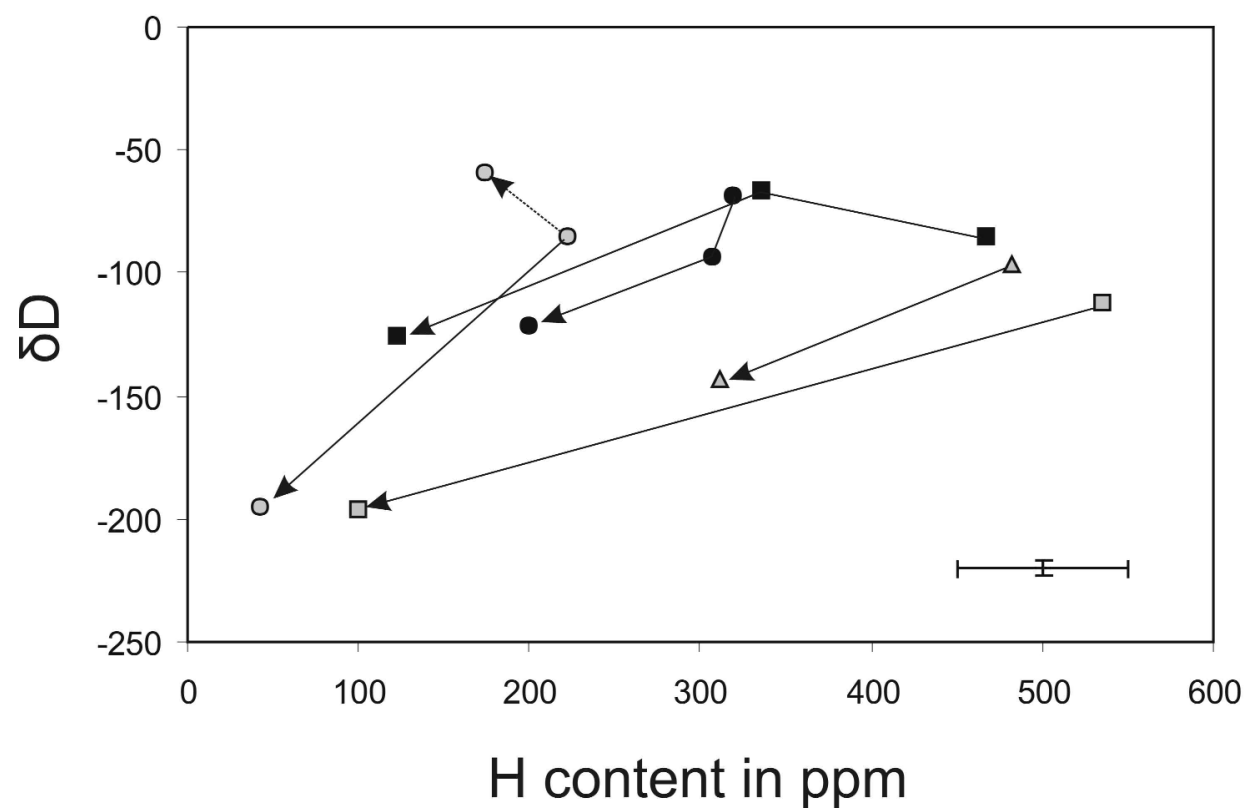

Fig. 5

$\mathrm{H}$ contents and stable hydrogen isotope compositions (in \%o relative to V-SMOW) of carbonado samples. Tie-lines connect data obtained for the same sample using different treatments (untreated HCl-treated - HCl\&HF-treated, and stepwise combustion)

whereas the $1000{ }^{\circ} \mathrm{C}$ and the $>1500{ }^{\circ} \mathrm{C}$ steps yielded $-204 \%$ ond $+38 \%$, respectively. The $\delta \mathrm{D}$ difference in the two high-temperature steps can be attributed to the very slow hydrogen diffusion out of the diamond structure (Foreman et al. 1999) that would result in preferential escape of the light isotope and enrich the remaining material in the heavy isotope. Thus, the results of the two steps were combined on the base of $\mathrm{H}$ yields (see Table 1 ), obtaining a $\delta \mathrm{D}$ value of $-195 \%$, in remarkable agreement with the low $\delta \mathrm{D}$ range observed for the $\mathrm{HCl}+\mathrm{HF}$-treated samples (Table 1).

\section{Discussion}

Formation of the carbonado textures and pore-filling minerals

Observations on textural features of carbonado grains can provide important information regarding formation processes (e.g. Petrovsky et al. 2010). The alignment of elongated pores and their concentration in zones within the carbonado grain (see Fig. 3C) is very similar to fluidized zones of vesicular basalts, and has been interpreted as a flow structure and sign of formation in a fluid-rich environment by Trueb and de Wys 1969; Yokochi et al. 2008). These zones bear no relation to the margins of the carbonado grain (Fig. 3B and C) so 
their formation is not related to the process that induced surface smoothening. The pores were already filled with minerals (but not with florencite as this $\mathrm{H}_{2} \mathrm{O}$ rich mineral would be decomposed during the high-temperature influence at least at the margins), otherwise they would have been in contact with ambient environment (hot fluid and/or melt) and hence the inner surface of empty pores would have also been smoothened. The large variations in cathodoluminescence (CL) colour both within individual grains and between localities indicate changing formation environment. This compositional - and most probably formation condition - variability is reflected by the heterogeneous behaviour of carbon isotope composition and nitrogen content that show different relationships between samples and localities (De et al. 2001; Yokochi et al. 2008). Although these authors interpreted CL colour varations in carbonado as an indication of changing formation conditions, in this investigation the CL colour shows no significant change at the margins even where the recrystallized zone reaches 50 micrometer thickness. This observation suggests that the ambient environment during the "fusion" was not very much different from that of the diamond formation, otherwise the margin should show changes in nitrogen, hydrogen and trace element contents, thought to be responsible for CL characteristics (Taylor and Anand 2004). In case of low nitrogen and hydrogen fugacities, the diamond would release these trapped volatiles during the recrystallization, which should result in some CL colour change.

The presumed high-temperature influence (tentatively called "fusion") that caused recrystallization at the margin and surface smoothening did not affect the inner surface of the pores, suggesting that the pores were already filled with minerals during the fusion process. The pore-filling minerals could not be the present-day assemblage as the florencite and kaolinite are sensitive to the high temperature and would suffer breakdown. Thus, the florencite and kaolinite should have had precursor minerals, such as feldspars and monazite (whose alteration can produce florencite; Rasmussen and Muhling 2009), both reported from carbonado by Trueb and de Wys (1969; 1971). As the carbonado-hosted florencite contains several wt\% Sr (Table 1, and see also De et al. 1998), it was suspected that a part of this high Sr content may be related to the precursor REE mineral, hereby providing clues to the origin of the initial pore-filling minerals. As a powerful tool for the determination of $\mathrm{Sr}$ origin, $87 \mathrm{Sr} / 86 \mathrm{Sr}$ ratios were measured in the $\mathrm{HCl}$-soluble fraction (related practically to the florencite). The 87Sr/86Sr ratios obtained are high compared to typical mantle compositions $(<0.705)$ and consistent with a crustal origin. Taking the presence of hydrous minerals typically formed at low-temperatures (kaolinite) into account, the most plausible explanation is that the formation of pore-filling florencite and kaolinite is related to late-stage influx of crustal fluids and complete alteration of the original mineral assemblage. This observation would be in accordance with the rare earth element compositions characteristic for crustal rocks detected in some carbonados (Shibata et al. 1993), although other carbonado samples yielded 
kimberlitic signatures (Kagi et al. 1994). This variation can be related to differences in the original mineral composition, or to the varying degree of alteration. The near-complete alteration of the original mineral assemblage even in the inner parts of carbonado grains requires interconnection of the pores. This was demonstrated by Dismukes et al. (1988) who were able to remove all the nondiamond minerals by one-week long sequential leaching, providing an analogue for the much longer natural alteration processes such as metamorphism or surficial alteration. Interestingly, native metal inclusions have been preserved in carbonado (Gorshkov et al. 1996; De et al. 1998) in spite of the late-stage alteration. Formation of native metals would indicate strongly reducing conditions, that would, however, not be unprecedented as native iron inclusions have also been encountered in kimberlitic diamonds from Siberia (Sobolev et al. 1981) and South Africa (Jacob et al. 2004).

\section{Hydrogen isotope compositions: possible alteration effects and primary compositions}

Bulk carbonado samples, which contains secondary, alteration-related minerals (florencite and kaolinite), yielded $-84 \pm 11 \%$, which composition can be considered as typical for any terrestrial (mantle or crust) reservoir (Hoefs 1996). The diamond structure itself contains about $70 \pm 30 \mathrm{ppm}$ hydrogen and this diamond-related hydrogen has a $\delta \mathrm{D}$ range of -200 to $-130 \%$ (Fig. 5). This composition is lower than usual mantle or crustal ranges, but it is still in the range of terresterial organic matter and hydrocarbons (Hoefs 1996).

The obtained hydrogen isotope compositions is consistent with formation of carbonado in the mantle or in the crust. However, it should be investigated if the $\delta \mathrm{D}$ range can also be reconciled with impact or an extraterrestrial origin (see Introduction). As hydrogen isotope compositions of extraterrestrial materials can be extremely different from terrestrial values (see reviews by Aléon and Robert 2004; Huss 2005), strong effects should have influenced the carbonado in order to achieve the present compositions if starting from extraterrestrial values. The responsible processes should have either i) introduced hydrogen into the diamond structure, ii) caused exchange with terrestrial $\mathrm{H}$ reservoirs, or iii) should have resulted in partial hydrogen loss and large isotope fractionation. The recrystallization at the margins of carbonado grains ("fusion crust") and the thorough alteration of pore-filling mineral assemblages suggest interactions at different temperatures that may have induced degassing or isotope exchange. All of these processes require migration of hydrogen in the diamond structure, thus, the possibility of hydrogen diffusion at relevant temperatures should be explored.

Several estimations of hydrogen diffusion rate at various temperatures have been published, reporting $\mathrm{D}$ values from about $10^{-15} \mathrm{~cm}^{2} \mathrm{~s}^{-1}\left(\sim 500^{\circ} \mathrm{C}\right.$, Teukam et al. 2003) to $2 \cdot 4 \cdot 10^{-13} \mathrm{~cm}^{2} \mathrm{~s}^{-1}\left(860^{\circ} \mathrm{C}\right.$, Popovici et al. 1995), so a diffusion rate of $10^{-13}$ to $10^{-13} \mathrm{~cm}^{2} \mathrm{~s}^{-1}$ can be roughly estimated for the temperature range of 
$1500-2000{ }^{\circ} \mathrm{C}$. An energy barrier of $1.9 \mathrm{eV}$ is given for $\mathrm{H}$ diffusion by Mehandru et al. (1992).

The pore-filling mineral assemblage of florencite and kaolinite suggests hydrothermal and metamorphic conditions followed by surficial weathering. Assuming a usual greenschist facies (see Smith and Dawson 1985; Martins-Neto 1996) metamorphic temperature up to $500{ }^{\circ} \mathrm{C}$, the necessary time required to diffuse hydrogen at various lengths can be calculated using the well-known Arrhenius equation $D=D_{0} \cdot e^{-E a / R T}$, where $E_{a}$ is the activation energy, $D_{o}$ is the diffusion coefficient, $\mathrm{R}$ is the gas constant, and $\mathrm{T}$ is temperature in $\mathrm{K}$. Based on our calculations, about 1012 years would be needed to have hydrogen diffusion at a length of 10 microns (an average crystallite size in carbonado matrix, as the crystal size actually ranges from $<1$ to several 100 microns), while diffusion through a 100 micron distance would require about $10^{15}$ years, diffusion of hydrogen into the diamond structure or isotope exchange with the ambient fluids at hydrothermal-metamorphic temperatures can be excluded. This means that i) the low $\delta \mathrm{D}$ values could not have been caused by preferential migration of the light hydrogen isotope into the diamond, and ii) the diamond structure was closed to isotope exchange and any extraterrestrial composition (very low or very high $\delta \mathrm{D}$ ) should have been preserved during the alteration process that produced the florencite-kaolinite assemblage.

Alternatively, a bolide impact would induce shock heating that can release trapped volatiles. Although there are a number of uncertainties concerning calculation of degassing effects (alteration temperature, duration, and fractionation between the escaping hydrogen and the remaining material), we can make some estimations. It is safe to assume that the hydrogen escapes as $\mathrm{H}_{2}$ and not as $\mathrm{H}_{2} \mathrm{O}$, taking preferentially the light isotope, and thus, causing Denrichment in the remaining carbonado. Consequently, the starting composition should be more D-depleted than the present-day composition, thus, in case of an initially deuterium-rich interstellar material dehydrogenation can in no way explain the observed $\delta \mathrm{D}$ range, as it must result in increasing $\delta \mathrm{D}$ values. If the initial composition of carbonado was around solar deuterium content of $\sim 20$ ppm ( -900\%; see Aléon and Robert 2004 and references therein), Rayleigh fractionation during degassing may cause a positive $\delta \mathrm{D}$ shift toward the observed compositions (from -200 to $-130 \%$ ). However, this would require a significant amount of hydrogen to leave the diamond structure. Using the diffusion parameters discussed above, the necessary time required to have $\mathrm{H}$ migration through a 10 micron distance would be on the order of $10^{2}$ to $10^{4}$ years at a temperature of 1200 to $2000{ }^{\circ} \mathrm{C}$ that is again unlikely to maintain after the impact. These considerations suggest that the hydrogen isotope compositions observed in pure carbonado diamond (i.e. completely demineralized by acid treatment) represent primary compositions. 
Terrestrial origin and possible relationships with other diamond types

The measured diamond-related hydrogen has a $\delta \mathrm{D}$ range from -200 to $-130 \%$ o which represents the hydrogen content trapped during the diamond formation. This composition is out of the range of extraterrestrial values, but similar to terrestrial hydrocarbons and organic matte. (Hoefs 1996). The additional constrain that a diamond with extraterrestrial origin should exhibit is its nitrogen isotope composition. For solar origin the $\delta^{15} \mathrm{~N}$ values should be down to $-350 \%$, while for interstellar matter the $\delta^{15} \mathrm{~N}$ values would range up to $+400 \%$ (Aléon and Robert 2004). The $\delta^{15} \mathrm{~N}$ values reported for carbonado are in the range of -17 to $+8 \%$ (Vicenzi and Heaney 2001; Heaney et al. 2005; Yokochi et al. 2008), which is practically equal with the mantle-derived peridotitic diamonds (Cartigny 2005). Diffusive alteration by terrestrial-like nitrogen isotope compositions can be excluded based on the very low diffusion rates in diamond.

Crustal organic matter have a wide range of $\delta^{13} \mathrm{C}$ and $\delta D$ values (Hoefs 1996), completely overlapping the diamond-related hydrogen isotope compositions obtained in this study. Methane formed biogenically or thermogenically during organic matter maturation has also similarly wide ranges, from which thermogenic methane compositions (Whiticar 1999) overlap the $\delta^{13} \mathrm{C}-\delta \mathrm{D}$ ranges of carbonado. Another possibility to explore is abiogenic hydrocarbons that may be formed in the deep Earth. Plotting the determined $\delta \mathrm{D}$ values against $\delta^{13} \mathrm{C}$ and comparing to mantle-derived hydrocarbon determined from inclusion fluids of alkaline magmatic rocks and other terrestrial sources it can be seen that the carbonado data fit well to the compositions of these mantle-derived hydrocarbons (Fig. 6). The so-called "normal mantle range" ( $\delta \mathrm{D}$ values around $-80 \%$; Boettcher and O'Neil 1980; Kyser and O'Neil 1984; Kyser 1986; $\delta^{13} \mathrm{C}$ values around -7 to $-5 \%$; Keller and Hoefs 1995; Deines 2002) is not shown in Fig. 6, as it refers to hydrous minerals, oxidized forms of mantle-derived carbon (carbonatites, xenolith-hosted $\mathrm{CO}_{2}$ ) and peridotitic diamonds which are certainly different from carbonado. It should be noted, however, that abiogenic methane and hydrocarbons from the Khibina alkaline complex have carbon and hydrogen isotope compositions close to the normal mantle compositions (similarly to the abiogenic methane compositions given by Whiticar 1999; Sherwood Lollar et al. 2002), with the higher hydrocarbons depleted in ${ }^{13} \mathrm{C}$ and ${ }^{2} \mathrm{H}$ relative to $\mathrm{CH}_{4}$ (Potter and Longstaffe 2007). These studies indicate that although mantle-derived hydrocarbons can be found with isotope values close to carbonado compositions, thermogenic methane would fit better to the observed $\delta^{13} \mathrm{C}-\delta \mathrm{D}$ ranges of carbonado. Either compared with mantle-derived C-H fluids, or crustal organic compounds, there is a significant overlap in carbon and hydrogen isotopic compositions, suggesting that carbonado may indeed have been formed from terrestrial carbon compounds.

Metasomatism by strongly reduced C-H fluids can explain the flow texture and the $\delta^{13} \mathrm{C}-\delta \mathrm{D}$ values of carbonado which is in accordance with earlier studies (Nadolinny et al. 2003; Kagi and Fukura 2008). This fluid may either have been 


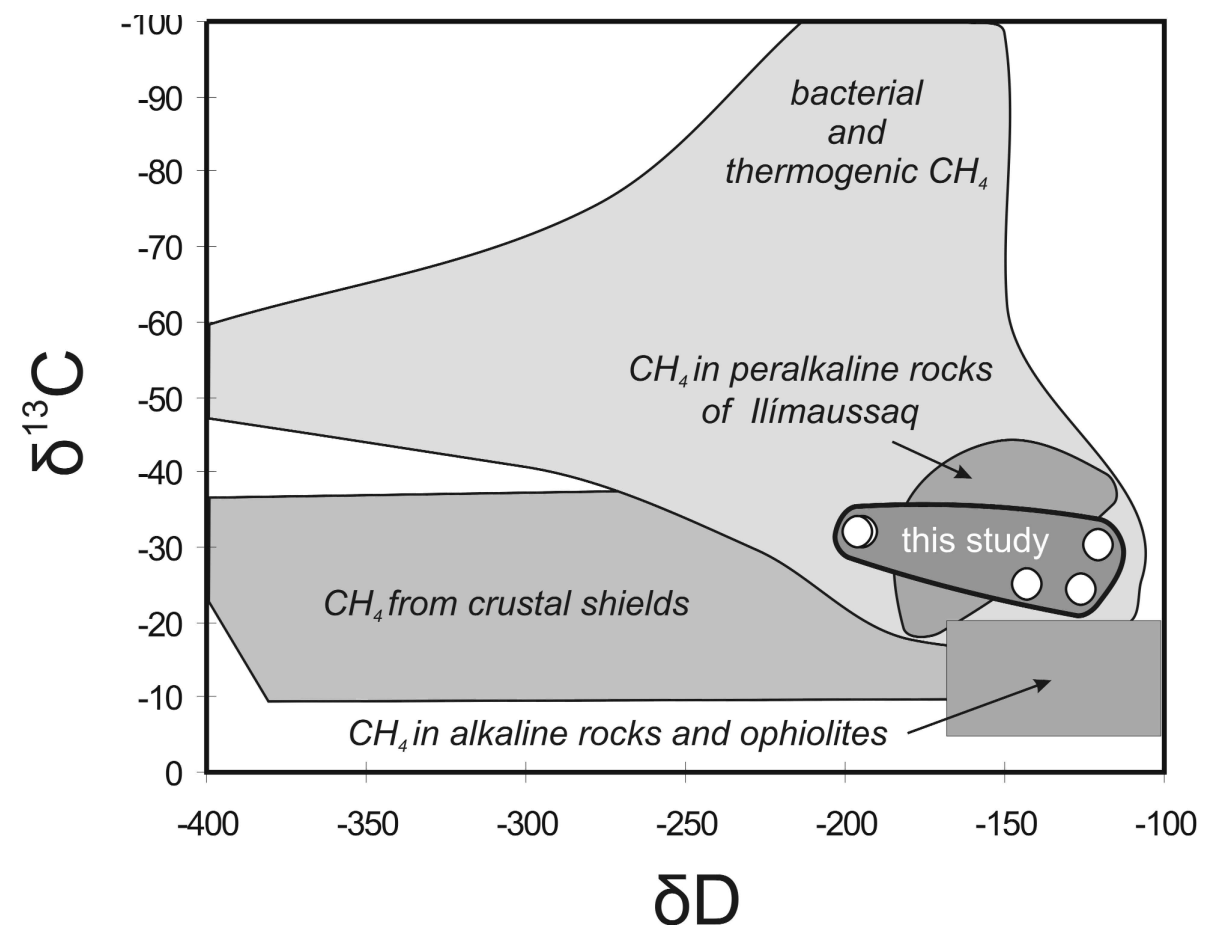

Fig. 6

Stable carbon and hydrogen isotope compositions (in \%o relative to V-PDB and V-SMOW, respectively) of carbonado (this study) and different terrestrial $\mathrm{CH}_{4}$ reservoirs (Graser et al. 2008)

mixed with REE-Sr-rich melt, resulting in an intermingled texture of diamond, REE- and silicate minerals, or a special rock type with REE-minerals and feldspar has to be assumed that was metasomatised. The former process would imply a carbonatitic melt (rich in REE and alkalies), analogous to the assumed formation of framesite diamond, whose low $\delta^{13} \mathrm{C}$ values and trace element characteristics lead (Jacob et al. 2000; Maruoka et al. 2004) to suggest formation from a C-H fluid and carbonatite melt. It is important to note that the possibility of transitional position of framesites between carbonado and eclogitic diamonds has already been raised by Heaney et al. (2005) and the lower end of the $\delta^{13} \mathrm{C}$ range of framesites overlaps with carbonado (Fig. 7), suggesting mixing of the very low $\delta^{13} \mathrm{C}$ fluid with a relatively ${ }^{13} \mathrm{C}$-enriched carbonatitic melt. The close relationship with framesites and the end-member characteristic of carbonado is also indicated by $\mathrm{N} \%-\delta^{15} \mathrm{~N}-{ }^{40} \mathrm{Ar}$ results (Yokochi et al. 2008). A further analogue to carbonado is the komatiite-hosted diamond found in French Guyana (Capdevila et al. 1999) that show striking similarities (low $\delta^{13} \mathrm{C}$ values, low $\mathrm{N}$ contents and aggregation states, Cartigny 2007; 2008) to carbonado raising the possibility of carbonado formation in the Earth's mantle. 
The other possibility is subduction of REE-rich crustal rock that reacted with a $\mathrm{C}-\mathrm{H}$ fluid. This process has been proposed as a mechanism for eclogitic diamond formation (e.g. Cartigny et al. 2004; Taylor and Anand 2004; De Stefano et al. 2009), thus, the observations presented in this paper are also compared to characteristics of eclogitic diamonds. The presence of K-feldspar may indicate genetic relationship with eclogitic diamonds as sanidine inclusions have been reported in this suite (e.g. Wang 1998; Sobolev et al. 1999; Taylor and Anand 2004). Further, carbon isotope compositions even lower than the carbonado range have been reported for eclogitic diamonds by Cartigny et al. (2004) and De Stefano et al. (2009) (Fig. 7). Green, orange and red cathodoluminescence colours unusual for mantle-derived diamonds but characteristic for carbonados have also been detected in calc-alkaline lamprophyre-related diamond populations (De Stefano et al. 2006) and orogenic microdiamonds (Yoshioka and Odasawara 2005), both

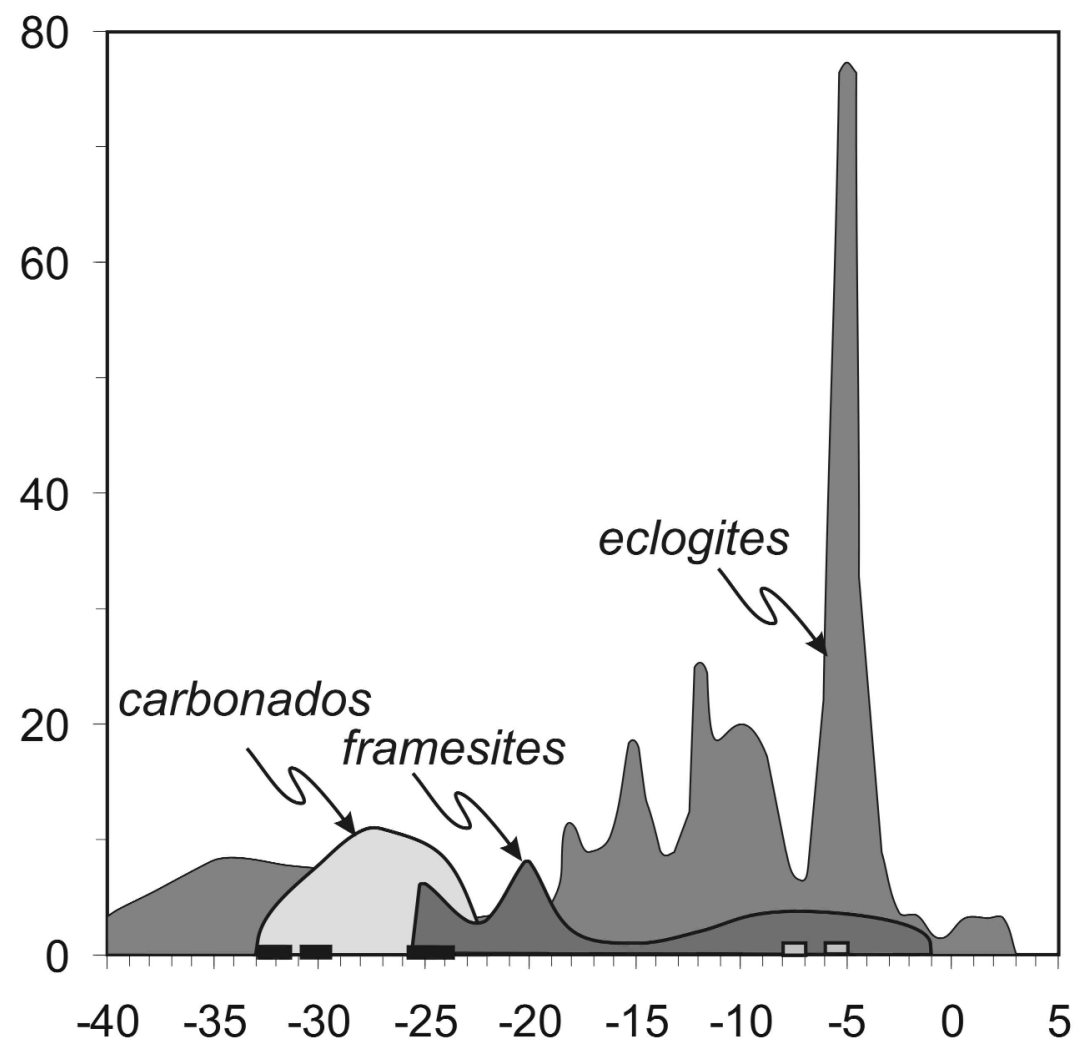

Fig. 7

Stable carbon isotope compositions (in \%o relative to V-PDB) of eclogitic diamonds (De Stefano et al. 2009; Stachel et al. 2009), framesites and carbonados (Heaney et al. 2005). Carbonado compositions compiled by Heaney et al. (2005) are plotted within the light grey field and two outliers as light grey squares (see their Figure 1), whereas data obtained in this study are marked by solid squares 
related to subduction processes. A further similarity with eclogitic diamonds is the low $\mathrm{N}$ content reported for carbonados. Figure 8 shows the $\delta^{13} \mathrm{C}$ vs. $\mathrm{N}$ content distribution of eclogitic diamonds (after Cartigny et al. 2004) as well as data for carbonados reported by Shelkov et al. (1997). It is apparent that the carbonado compositions plot within the eclogitic diamond field, close to framesites' data. It is interesting to note that low $-\delta^{13} \mathrm{C}$ zones in diamonds are also interpreted as formed from subducted crustal material by Schulze et al. (2004) (shown also in Fig. 8).

Either by mixing with mantle fluids/melts, or by interaction with subducted rocks, the low $\delta \mathrm{D}-\delta^{13} \mathrm{C}$ characteristics suggest the influence of a reduced $\mathrm{C}-\mathrm{H}$ fluid. Microcrystalline diamond could be precipitated due to reaction between the reduced fluids and silicate magma, similarly to the mechanism proposed for metamorphic diamonds (Sobolev and Shatsky 1990). $\mathrm{As}^{\mathrm{CH}_{4}}$ - and maybe higher hydrocarbons - are oxidized, metals are reduced to native form, and elemental carbon precipitates as diamond. Carbonado formation under mantle conditions

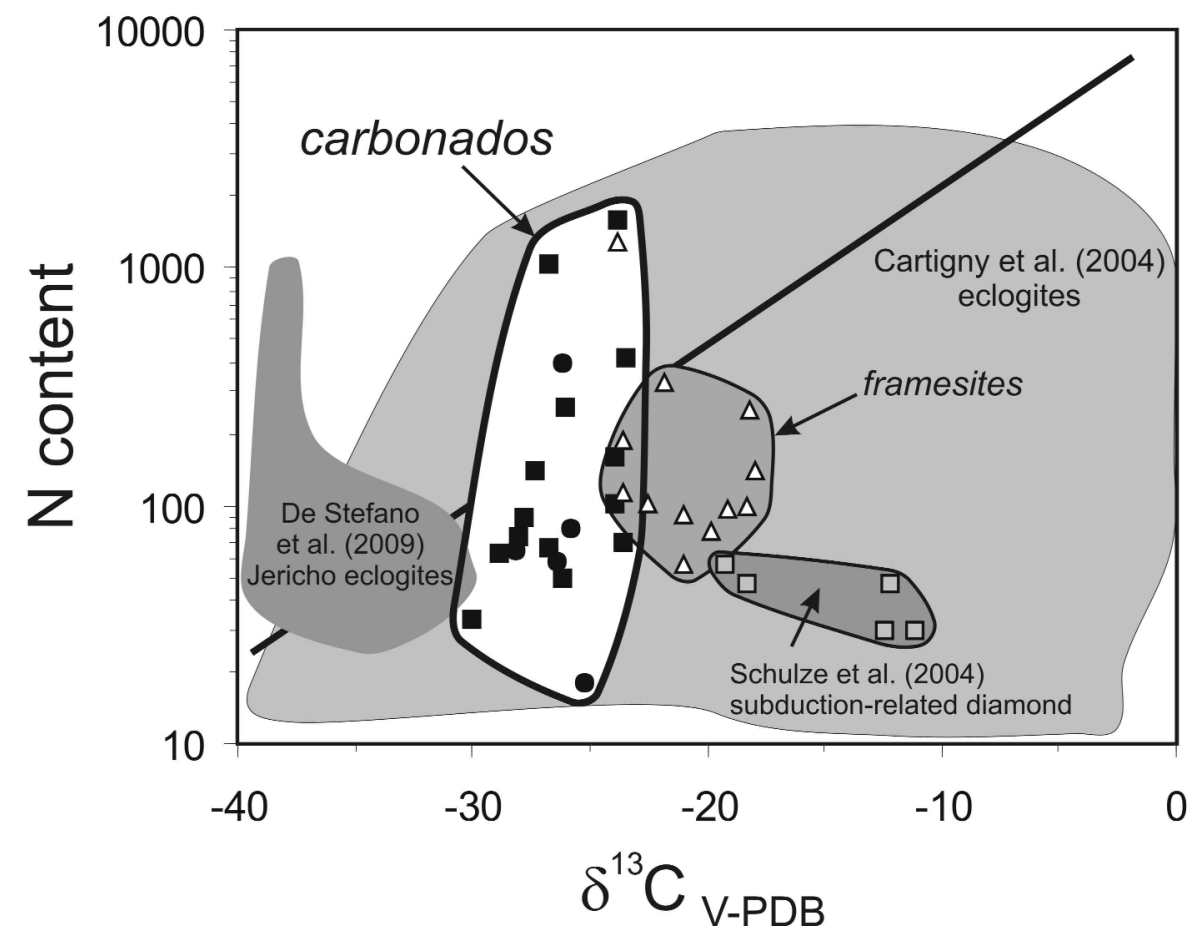

Fig. 8

Nitrogen content (in ppm) vs. carbon isotopic compositions (in \%o relative to V-PDB) for eclogitic diamonds worldwide (Cartigny et al. 2004) and in Jericho Mine, Canada (De Stefano et al. 2009), diamond-zones related to subducted material (Schulze et al. 2004), framesites and carbonados (Shelkov et al. 1997; solid circles: Ubangui, solid squares: Brasil). Solid line shows the limit of the eclogite sector (Cartigny et al. 2001) 
would also be supported by the presence of "large" (reaching several hundred micrometer size) octahedral crystals (Shelkov et al. 1997; De et al. 2001; Petrovsky et al. 2010), whose formation requires time.

The textural characteristics of carbonado suggest that the carbonado pieces suffered different degrees of recrystallization at their margins that may be related to a resorption effect by a high-temperature melt that transported the diamond pieces to the surface. Finally, after transportation to the surface by a magmatic pulse, weathering and deposition in placer deposits, metamorphism resulted in complete alteration of the original REE- and silicate minerals, producing the florencite and kaolinite mixture with small amounts of other crustal minerals like quartz and $\mathrm{TiO}_{2}$ (anatase in our samples).

This model would be consistent with our textural observations and chemical and $\mathrm{H}-\mathrm{C}-\mathrm{Sr}$ isotope compositions. It would put the formation of carbonado, framesite and similar polycrystalline diamond varieties discovered in Russia and China (containing also florencite, Gorshkov et al. 1996; Seliverstov et al. 1996; Titkov et al. 2001) in a common framework in which carbonado is an endmember, while other polycrystalline diamonds are transitional between carbonado and regular kimberlitic diamonds. The process is rather special, diamond precipitation induced by mantle metasomatism by strongly reduced carbonic fluids and their mixing with REE-rich melts, or by interaction of hydrocarbons with subducted REE-rich rocks would be very occasional. Thus, it is no surprise that such diamonds are found rarely and their occurrences are confined to certain areas. However, recent investigations report more and more diamond features which are similar to those observed for carbonado. Green and orange CL colours and low $\delta^{13} \mathrm{C}$ values are no more exclusively related to carbonado sensu stricto, and many new observations would be in agreement with a special formation process in the mantle.

\section{Conclusions}

This study presents the first hydrogen isotope composition analyses on carbonado diamond conducted in order to investigate the origin of hydrogen related to the diamond structure detected by earlier studies. The hydrogen of bulk carbonado (dominated by the $\mathrm{H}$ content of pore filling minerals) yielded $-84 \%$, consistent with an origin from either crustal or mantle-derived fluids. Textural characteristics and $\mathrm{Sr}$ isotope ratios indicate formation in a fluid-rich environment followed by a high temperature influence and finally by thorough alteration. The hydrogen component bound to the diamond shows a D-depletion down to -200 to $-130 \%$. Diffusion modelling of late stage alteration effects (either hydrogen incorporation during interaction with fluids or dehydrogenation during degassing) indicated that the diamond-related hydrogen most likely represent the original $\mathrm{H}$ content. The carbon and hydrogen isotope compositions of carbonado diamond overlap the $\delta \mathrm{D}$ and $\delta^{13} \mathrm{C}$ ranges of terrestrial 
organic compounds and abiogenic hydrocarbons. The $\mathrm{H}$ isotope data combined with textural evidence as well as with geochemical data of earlier studies are best explained with terrestrial formation, most probably by metasomatism of subducted crustal rocks or mantle rocks/melts by reduced $\mathrm{C}-\mathrm{H}$ fluids.

\section{Acknowledgments}

The mass spectrometer facility at the Institute of Geochemical Research was financed by the National Office for Research and Technology (GVOP-3.2.1-200404-0235/3.0). JG is indebted to Professor Stephen Haggerty for numerous discussions and for donation of the Brazilian carbonado. We sincerely thank Nikolay Sobolev, Dorrit Jacob and Hiroyuki Kagi for their thorough reviews that greatly helped clarify our ideas.

\section{References}

Aléon, J., F. Robert 2004: Interstellar chemistry recorded by nitrogen isotopes in Solar system organic matter. - Icarus, 167 , pp. 424-430.

Boettcher, A.L., J.R. O'Neil 1980: Stable isotope, chemical, and petrographic studies of high-pressure amphiboles and micas: evidence for metasomatism in the mantle source regions of alkali basalts and kimberlites. - Americal Journal of Science, 280-A, pp. 594-621.

Capdevilla, R., N. Arndt, J. Letendre, J.F. Sanvage 1999: Diamonds in volcaniclastic komatite from French Guiana. - Nature, 399, pp. 456-458.

Cartigny, P., T. Stachel, J. Harris, M. Javoy 2004: Constraining diamond metasomatic growth using Cand N-stable isotopes; examples from Namibia. - Lithos, 77, pp. 359-373.

Cartigny, P. 2005: Stable isotopes and the origin of diamond. - Elements, 1, pp. 79-84.

Cartigny, P. 2007: Mantle derived carbonados: insights from Dachine diamonds (French Guiana). Geochimica et Cosmochimica Acta, 71-A, pp. 148.

Cartigny, P. 2008: The formation of enigmatic carbonados from komatiite-related fluids: A model. Geochimica et Cosmochimica Acta, 72-A, pp. 141.

Cartigny, P., J.W. Harris, M. Javoy 2001: Diamond genesis, mantle fractionations and mantle nitrogen content: a study of $\delta^{13} \mathrm{C}-\mathrm{N}$ concentrations in diamonds. - Earth and Planetary Science Letters, 185, pp. 85-98.

De, S., P.J. Heaney, R.B. Hargreaves, E.P. Vicenzi, P.T. Taylor 1998: Mineralogical observations of polycrystalline diamond - a contribution to the carbonado conundrum. - Earth and Planetary Science Letters, 164, pp. 421-433.

De, S.R., P.J. Heaney, E.P. Vicenziand, J.H. Wang 2001: Chemical heterogeneity in carbonado, an enigmatic polycrystalline diamond. - Earth and Planetary Science Letters, 185, pp. 315-330.

De, S., P.J. Heaney, Fei Yungwei, E.P. Vicenzi 2004: Microstructural study of synthetic sintered diamond, and comparison with carbonado, a natural polycrystalline diamond. - American Mineralogist, 89, pp. 438-446.

De Stefano, A., N. Lefebvre, M. Kopylova 2006: Enigmatic diamonds in Archean calc-alkaline lamprophyres of Wawa, southern Ontario, Canada. - Contributions to Mineralogy and Petrology, 151, pp. 158-173.

De Stefano, A., M.G. Kopylova, P. Cartigny, V. Afanasiev 2009: Diamonds and eclogites of the Jericho kimberlite (Northern Canada). - Contributions to Mineralogy and Petrology, 158, pp. 295-315.

Deines, P. 2002: The carbon isotope geochemistry of mantle xenoliths. - Earth-Science Reviews, 58, pp. 247-278. 
Demény, A. 1995: H isotope fractionation due to hydrogen-zinc reactions and its implications on D/H analysis of water samples. - Chemical Geology, 121, pp. 19-25.

Demény, A., Z. Siklósy 2008: Combination of off-line preparation and continuous flow mass spectrometry: $\mathrm{D} / \mathrm{H}$ analyses of inclusion waters. - Rapid Communications in Mass Spectrometry, 22, pp. 1329-1334.

Dismukes, J.P., P.R. Gaines, H. Witzke, D.P. Leta, B.H. Kear, S.K. Behal, S.B. Rice 1988: Demineralisation and microstructure of carbonado. - Materials Science and Engineering, A105/106, pp. 555-563.

Dobrzhinetskaya, L., R. Wirth, J. Yang, I. Hutcheon, P. Weber, H.W. Green 2007: Osbornite (TiN) and boron nitride nanoinclusions in coesite from Tibet: a first record of nitrogen in a terrestrial ultrahigh pressure environment. - American Geophysical Union, Fall Meeting, 2007, abstract \#V43E-04.

Foreman, L.R., R.S. Barbero, D.W. Carroll, T. Archuleta, J. Baker, D. Devlin, J. Duke, D. Loemier, M. Trukla 1999: Diamond and Diamond-Like Materials as Hydrogen Isotope Barriers. - DOE Scientific and Technical Information, DOI 10.2172/759179.

Galimov, E.M., FV. Kaminskii, L.A. Kodina 1985: New data on isotopic composition of carbon in carbonado. - Geokhimiya, 5, pp. 723-726.

Garai, J., S.E. Haggerty, S. Rekhi, M. Chance 2006: Infra-red absorption investigations confirm the extraterrestrial origin of carbonado diamonds. - Astrophysical Journal, 653, pp. L153-L156.

Gorshkov, A.I., S.V. Titkov, A.M. Pleshakov, A.V. Sivtsov, L.V. Bershov 1996: Inclusions of native metals and other mineral phases into carbonado from the Ubangi region (Central Africa). Geology of Ore Deposits, 38, pp. 114-119.

Graser, G., J. Potter, J. Köhler, G. Markl 2008: Isotope, major, minor and trace element geochemistry of late-magmatic fluids in the peralkaline Ilímaussaq intrusion, South Greenland. - Lithos, 106, pp. 207-221.

Haggerty, S.E. 1996: Diamond-carbonado models for a new meteorite class of circumstellar or solar system origin. - EOS, 77, pp. S143.

Haggerty, S.E. 1999: A diamond trilogy: superplumes, supercontinents, and supernovae. - Science, 285, pp. 851-860.

Hayman, P.C., M.G. Kopylova, FV. Kaminsky 2005: Lower mantle diamonds from Rio Soriso (Juina area, Mato Grosso, Brazil). - Contributions to Mineralogy and Petrology, 149, pp. 430-445.

Heaney, P.., E.P. Vicenziand, E. Breval 2004: The origin of porosity in carbonado diamond. Geochimica et Cosmochimica Acta, 68, pp. A115.

Heaney, P.J., E.P. Vicenzi, S. De 2005: Strange diamonds: the mysterious origins of carbonado and framesite. - Elements, 1, pp. 85-89.

Hegner, E., H.J. Walter, M. Satir 1995: Pb-Sr-Nd isotopic compositions and trace element geochemistry of megacrysts and melilites from the Tertiary Urach volcanic field: source composition of small volume melts under SW Germany. - Contributions to Mineralogy and Petrology, 122, pp. 322-335.

Hoefs, J. 1996: Stable isotope geochemistry. - Springer-Verlag, $201 \mathrm{p}$.

Huss, G.R. 2005: Meteoritic nanodiamonds: Messengers from the stars. - Elements, 1, pp. 97-100.

Jacob, D.E., K.S. Viljoen, N. Grassineau, E. Jagoutz 2000: Remobilization in the cratonic lithosphere recorded in polycrystalline diamond. - Science, 289, pp. 1182-1185.

Jacob, D.E., A. Kronz, K.S. Viljoen 2004: Cohenite, native iron and troilite inclusions in garnets from polycrystalline diamond aggregates. - Contributions to Mineralogy and Petrology, 146, pp. 566-576.

Jones, A.P., A.D. Beard. J. Milledge, G. Cressey, C. Kirk, P. DeCarli 2003: New nitride minerals in carbonado diamond. - Eighth International Kimberlite Conference Abstracts, Victoria Canada, FLA 0167.

Kagi, H. S. Fukura 2008: Infrared and Raman spectroscopic observations of Central African carbonado and implications for its origin. - European Journal of Mineralogy, 20, pp. 387-393. 
Kagi, H., K. Takahashi, H. Hidaka, A. Masuda 1994: Chemical properties of Central American carbonado and its implications. - Geochimica et Cosmichimica Acta, 58, pp. 2629-2638.

Kagi, H., S. Sato, T. Akagi, H. Kanda 2007: Generation history of carbonado inferred from photoluminescence spectra, cathodoluminescence image and carbon isotopic composition. American Mineralogist, 92, pp. 217-224.

Kagi, H., H. Sakurai, H. Ishibashi, H. Ohfuji 2010: Finding primary fluid inclusions in carbonado diamond and its implication to the origin. - Acta Mineralogica et Petrographica, Abstract Series, International Mineralogical Association 2010, pp. 178.

Kaminskiy, F.V. 1987: Genesis of carbonado-polycrystalline aggregates of diamond. - Akademiya Nauk SSSR Doklady, Earth Sciences Section, 294, pp. 439-440.

Kaminsky, FV. 1991: Carbonado and yakutite: Properties and possible genesis. - Proceedings of the International Kimberlite Conference, 5, pp. 214-216.

Kamioka, H., K. Shibata, I. Kajizuka, T. Ohta 1996: Rare-earth element patterns and carbon isotopic composition of carbonados: Implications for their crustal origin. - Geochemical Journal, 30, pp. 189-194.

Keller, J., J. Hoefs 1995: Stable isotope characteristics of recent natrocarbonatites from Oldoinyo Lengai. - In: Bell, K., J. Keller (Eds): Carbonatite Volcanism: Oldoinyo Lengai and the Petrogenesis of Natrocarbonatites. Springer Verlag, Berlin, Heidelberg, New York, London, Paris, Tokyo, Hong Kong, Barcelona, Budapest, pp. 113-123.

Kletetschka, G., P.T. Taylor, P.J. Wasilewski, H.G.M. Hill 2000: Magnetic properties of aggregate polycrystalline diamond: implications for carbonado history. - Earth and Planetary Science Letters, 181, pp. 279-290.

Kyser, TK. 1986: Stable isotope variations in the mantle. - In: Valley, J.W., H.P. Taylor, Jr., J.R. O'Neil (Eds): Stable isotopes in high temperature geological processes. Reviews in Mineralogy, Mineralogical Society of America, 16, pp. 141-164.

Kyser, T.K., J.R. O'Neil 1984: Hydrogen isotope systematics of submarine basalts. - Geochimica et Cosmochimica Acta, 48, pp. 2123-2133.

Martins-Neto, M.A. 1996: Lacustrine fan-deltaic sedimentation in a Proterozoic rift basin: the SopaBrumadinho Tectonosequence, southeastern Brazil. - Sedimentary Geology, 106, pp. 65-96.

Maruoka, T., G. Kurat, G. Dobosi, C. Koeberl 2004: Isotopic composition of carbon in diamonds of diamondites: Record of mass fractionation in the upper mantle. - Geochimica et Cosmochimica Acta, 68, pp. 1635-1644.

Mehandru, S.P., A.B. Anderson, J.C. Angus 1992: Hydrogen binding and diffusion in diamond. Journal of Materials Research, 73, pp. 689-695.

Nadolinny, V.A., V.S. Shatsky, N.V. Sobolev, D.J. Twitchen 2003: Observation and interpretation of paramagnetic defects on Brazilian and Central African carbonados. - American Mineralogist, 88, pp. 11-17.

Ozima, M., M. Tatsumoto 1997: Radiation-induced diamond crystallization: Origin of carbonados at its implication on meteoritic nano-diomonds. - Geochimica et Cosmochimica Acta, 61, pp. 369-376.

Ozima, M., S. Zashu, K. Tomura, Y. Matsuhisa 1991: Constraints from noble-gas contents on the origin of carbonado diamonds. - Nature, 351, pp. 472-474.

Parthasarathy, G., S.E. Haggerty, A.C. Kunwar 2005: Nanocrystalline osbornite from carbonados: spectrographic studies. - Geochimica et Cosmochimica Acta, 69 Supplement, pp. 521.

Petrovsky, V.A., A.A. Shiryaev, V.P. Lyutoev, A.E. Sukharev, M. Martins 2010: Morphology and defects of diamond grains in carbonado: clues to carbonado genesis. - European Journal of Mineralogy, 22, pp. 35-47.

Popovici, G., R.G. Wilson, T. Sung, M.A. Prelas, S. Khasawinah 1995: Diffusion of boron, lithium, oxygen, hydrogen, and nitrogen in type IIa natural diamond. - Journal of Applied Physics, 77, pp. 5103-5106.

Potter, J., FJ. Longstaffe 2007: A gas-chromatograph, continuous flow-isotope ratio massspectrometry method for $\delta^{13} \mathrm{C}$ and $\delta \mathrm{D}$ measurement of complex fluid inclusion volatiles: 
Examples from the Khibina alkaline igneous complex, northwest Russia and the south Wales coalfields. - Chemical Geology, 244, pp. 186-201.

Rasmussen, B., J.R. Muhling 2009: Reactions destroying detrital monazite in greenschist-facies sandstones from the Witwatersrand basin, South Africa. - Chemical Geology, 264, pp. 311-327.

Robinson, D.N. 1978: The characteristics of natural diamond and their interpretation. - Minerals Science, 10, pp. 55-72.

Schulze, D.J., B. Harte, J.W. Valley, D.M.D. Channer 2004: Evidence of subduction and crust-mantle mixing from a single diamond. - Lithos, 77, pp. 349-358.

Seliverstov, V.A., A.I. Gorshkov, S.A. Shcheka, A.V. Sivtsov 1996: Diamonds and carbonado of the Primorskii Krai: Mineralogy, crystal chemistry, and genesis. - Geology of Ore Deposits, 38, pp. 429-441.

Shang, L., I.-M. Chou, W. Lu, R.C. Burruss, Y. Zhang 2009: Determination of diffusion coefficients of hydrogen in fused silica between 296 and $523 \mathrm{~K}$ by Raman spectroscopy and application of fused silica capillaries in studying redox reactions. - Geochimica et Cosmochimica Acta, 73, pp. $5435-5443$.

Shelkov, D., A.B. Verchovsky, H.J. Milledge, C.T. Pillinger 1997: Carbonado: a comparison between Brazilian and Ubangui sources with other forms of microcrystalline diamond baseb on carbon and nitrogen isotopes. - Russian Geology and Geophysics, 38, 332-340.

Sherwood Lollar, B., T.D. Westgate, J.A. Ward, G.F. Slater, G. Lacrampe-Couloume 2002: Abiogenic formation of alkanes in the Earth's crust as a minor source for global hydrocarbon reservoirs. Nature, 6880, pp. 522-524.

Shibata, K., H. Kamioka, FV. Kaminsky, V.I. Koptil, D.P. Svisero 1993: Rare earth element patterns of carbonado and yakutite: evidence for their crustal origin. - Mineralogical Magazine, 57, pp. 607-611.

Smith, J.V., J.B. Dawson 1985: Carbonado diamond aggregates from early impacts of crustal rocks. Geology, 13, pp. 342-343.

Sobolev, N.V., V.S. Shatsky 1990: Diamond inclusions in garnets from metamorphic rocks: a new environment for diamond formation. - Nature, 343, pp. 742-746.

Sobolev, N.V., E.S. Efimova, L.N. Pospelova 1981: Native iron in diamonds of Yakutiya and its paragenesis. - Geologiya i Geofizika, 22, pp. 25-28.

Sobolev, N.V., E.S. Efimova, V.I. Koptil 1999: Mineral inclusions in diamonds in the Northeast of the Yakutian diamondiferous province. - Proceedings of the 7th Kimberlite Conference, pp. 816-821.

Stachel, T., J.W. Harris, K. Muehlenbachs 2009: Sources of carbon in inclusion bearing diamonds. Lithos, 112S, pp. 625-637.

Taylor, L.A., M. Anand 2004: Diamonds: time capsules from Siberian mantle. - Chemie der Erde, 64, pp. 1-74.

Teukam, Z., D. Ballutaud, F. Jomard, J. Chevallier, M. Bernard, A. Deneuville 2003: Trap limited diffusion of hydrogen in boron-doped diamond. - Diamond and Related Materials, 12, pp. 647-651.

Titkov, S.V., A.I. Gorshkov, S.F Vinokurov, L.V. Bershov, D.I. Solodov, A.V. Sivtov 2001: Geochemistry and genesis of carbonado for Yakutian diamond deposits. - Geochemistry International, 39, pp. $228-236$.

Trueb, L.F., W.C. Butterman 1969: Carbonado, a microstructural study. - American Mineralogist, 54, pp. 412-425.

Trueb, L.F., E.C. de Wys 1969: Carbonado: Natural polycrystalline diamond. - Science, 165, pp. 799-802.

Trueb, L.C., E.C. de Wys 1971: Carbon from Ubangui. - American Mineralogist, 56, pp. 1252-1268.

Vicenzi, E.P., P.J. Heaney 2001: The Carbon and Nitrogen Isotopic Composition of Carbonado Diamond: An In Situ Study. - Eleventh Annual V. M. Goldschmidt Conference abstract, pp. 3886. 
Vinogradov, A.P., O.I. Kropotova, Y.L. Orlov, V.A. Grinenko 1966: Isotopic composition of diamond and carbonado crystals. - Geochemistry International, 3, pp. 1123-1125.

Wang, W. 1998: Formation of diamond with mineral inclusions of "mixed" eclogite and peridotite paragenesis. - Earth and Planetary Science Letters, 160, pp. 831-843.

Whiticar, M.J. 1999: Carbon and hydrogen isotope systematics of bacterial formation and oxidation of methane. - Chemical Geology, 161, pp. 291-314.

Yokochi, R., D. Ohnenstetter, Y. Sano 2008: Intragrain variation in $\delta^{13} \mathrm{C}$ and nitrogen concentration associated with textural heterogeneities of carbonado. - Canadian Mineralogist, 46, pp. 1283-1296.

Yoshioka, N., Y. Odasawara 2005: Cathodoluminescence of microdiamond in dolomite marble from the Kokchetav Massif - Additional evidence for two-stage growth of diamond. - International Geology Review, 47, pp. 703-715.

Zashu, S., H. Hiyagon 1995: Degassing mechanisms of noble gases from carbonado diamonds. Geochimica et Cosmochimica Acta, 59, pp. 1321-1328. 